\title{
BENCHMARKING OF FINITE ELEMENT CODES FOR RADIOACTIVE MATERIAL TRANSPORTATION PACKAGES*
}

\author{
Douglas J. Ammerman \\ Sandia National Laboratories \\ Transportation Systems Department \\ P.O. Box 5800 \\ Albuquerque, New Mexico 87185-0717 \\ Tel: 505-845-8158 \\ Fax: 505-844-0244 \\ email: djammer@sandia.gov
}

\begin{abstract}
The increased power of computers and computer codes makes the use of nonlinear dynamic finite element analyses attractive for use as a tool used in the design and certification of radioactive material transportation packages. For this analysis technique to be acceptable it must be demonstrated the technique has the ability to accurately capture the response of the packages to accident environments required by the regulations. The best method of demonstrating this ability is via a series of benchmark analyses. In this paper three benchmark problems involving significant inelastic deformations will be discussed. One of the problems has been analyzed using many different finite element codes. The other two problems involve comparison of finite element calculations to the results from physical tests. The ability of the finite element method to accurately capture the response in these three problems indicates the method should be acceptable for radioactive material transportation package design and certification.
\end{abstract}

\section{INTRODUCTION}

Packages for the transportation of large quantities of radioactive materials are designed to withstand a series of hypothetical accidents. One of these accidents is a free fall from a height of nine meters onto an essentially unyielding target in the orientation that is most likely to damage the package. Frequently, this is the accident environment that governs the structural design of the package. For this reason, the benchmark problems investigated consisted of impacts with a velocity similar to that from a 9-meter free fall $(13.4 \mathrm{~m} / \mathrm{s})$. For most packages, the design is such that this impact results in very little plastic deformation to the containment boundary of the package. Other components of the package may experience extensive plastic strains. Some of these high-strain components include the lead gamma shielding

\footnotetext{
* This work was supported by the U. S. Department of Energy under Contract No. DE-AC04-94AL85000.
}

used in some packages, the impact limiters, and exterior shells, such as might be present outside of a layer of neutron absorbing material. Other applications where packages may see significant inelastic strains is for impacts more severe than the design basis impact. It is important to study these impact when performing risk assessments for shipping campaigns to address the response to very low probability but potentially higher consequence events.

The remaining sections of this paper will discuss the three benchmarking activities performed at Sandia National Laboratories. The final section will provide some conclusions and recommendations for the use of inelastic analysis techniques in the design and certification of radioactive material transportation packages.

\section{LEAD-SLUMP TUBE IMPACT}

The first problem investigated was the impact of concentric steel and lead cylinders onto a rigid surface at $13.4 \mathrm{~m} / \mathrm{s}$, as proposed by Glass (1985). The dimensions are as shown in Fig. 1. In this problem the steel is elastic/perfectly plastic. The lead and steel are attached at a single point at the impacting end of the cylinder, with frictionless surfaces elsewhere. This allows the lead to slide down the inside of the steel cylinder. The amount the lead cylinder shortens relative to the steel cylinder is known as "slump". In radioactive material packages the amount of lead slump is important, as it can lead to a radiation streaming path. Analyses were performed using axi- symmetric models with HONDO II, MANJUSRI-2D, PISCES-2DELK, ANSYS, and PRONTO-2D (Taylor and Flanagan, 1987). In addition, a 3D analysis was performed using PRONTO-3D (Taylor and Flanagan 1989). Figure 2 shows the finite element meshes used for the PRONTO-2D and PRONTO-3D analyses. All of the other analyses used much coarser meshes, as they were performed in the late 1980's and the available computers at that time could not readily handle problems of the size that is now possible. Table 1 shows the results from the analyses. The first 


\section{DISCLAIMER}

Portions of this document may be illegible in electronic image products. Images are produced from the best available original document. 


\section{DISCLAIMER}

This report was prepared as an account of work sponsored by an agency of the United States Government. Neither the United States Government nor any agency thereof, nor any of their employees, makes any warranty, express or implied, or assumes any legal liability or responsibility for the accuracy, completeness, or usefulness of any information, apparatus, product, or process disclosed, or represents that its use would not infringe privately owned rights. Reference herein to any specific commercial product, process, or service by trade name, trademark, manufacturer; or otherwise does not necessarily constitute or imply its endorsement, recommendation, or favoring by the United States Government or any agency thereof. The views and opinions of authors expressed herein do not necessarily state or reflect those of the United States Government or any agency thereof. 
four results were reported previously by Glass, and the two PRONTO results are from recent analyses. The newer PRONTO results agree quite well with the consensus solution obtained from the earlier work.

Table 1: Analysis results for lead-slump problem

\begin{tabular}{|c|c|c|c|c|}
\hline Analysis & $\begin{array}{c}\text { Duration } \\
(\mathrm{ms})\end{array}$ & $\begin{array}{c}\text { Lead } \\
\text { Slump }\end{array}$ & $\begin{array}{c}\text { Steel } \\
\text { Deformation } \\
(\mathrm{m})\end{array}$ & $\begin{array}{c}\text { Rebound } \\
\text { Velocity } \\
(\mathrm{m} / \mathrm{s})\end{array}$ \\
\hline \hline HONDO II & 30.2 & 0.198 & 0.018 & 0.804 \\
\hline MANJUSRI-2D & 30.8 & 0.20 & 0.024 & 0.83 \\
\hline PISCES-2DELK & 30.2 & 0.20 & 0.021 & 0.86 \\
\hline ANSYS & 23.6 & 0.117 & 0.0328 & $\mathrm{NA}$ \\
\hline PRONTO-2D & 29.3 & 0.203 & 0.0213 & 0.772 \\
\hline PRONTO-3D & 30.9 & 0.204 & 0.0191 & 0.710 \\
\hline
\end{tabular}

\section{LARGE INELASTIC DEFORMATION BENCHMARK}

For the purposes of evaluating nonlinear finite element analysis codes, it was desirable for the benchmark problem to produce large amounts of plasticity and buckling. One type of problem that includes these two behaviors is the generation and collapse of a buckle. Because most radioactive material transportation packages use cylindrical components, a cylinder buckling problem was chosen for the benchmark exercise (Hoffman and Ammerman, 1995). To have a true buckling problem with cylindrical geometry, it is necessary to load the cylinder with axial compression. This can be accomplished in two ways - using the weight of the cylinder and high accelerations to initiate the buckle or using added mass with lower accelerations. Because the impact velocity for the hypothetical accident test of radioactive material transportation packages is relatively low $(13.4 \mathrm{~m} / \mathrm{s}$ or $30 \mathrm{MPH})$ it is easier to get buckle initiation and collapse using added mass. With this alternative there are two methods of applying the acceleration pulse to the cylinder -dropping the cylinder and added mass together onto a stiff target or dropping the added mass onto the cylinder resting on a stiff target. To

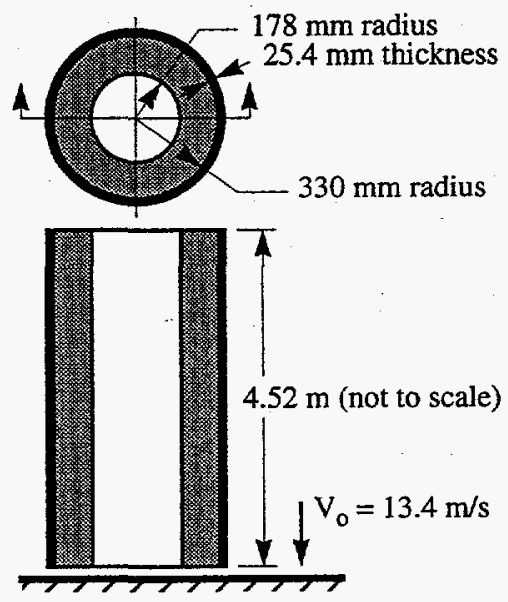

Figure 1: Lead-slump tube impact problem
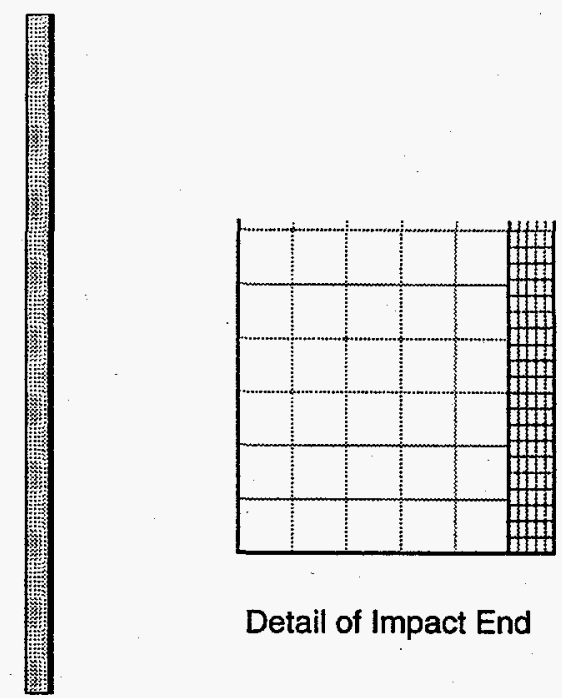

Detail of Impact End

\section{Axisymmetric mesh used for PRONTO-2D analysis}
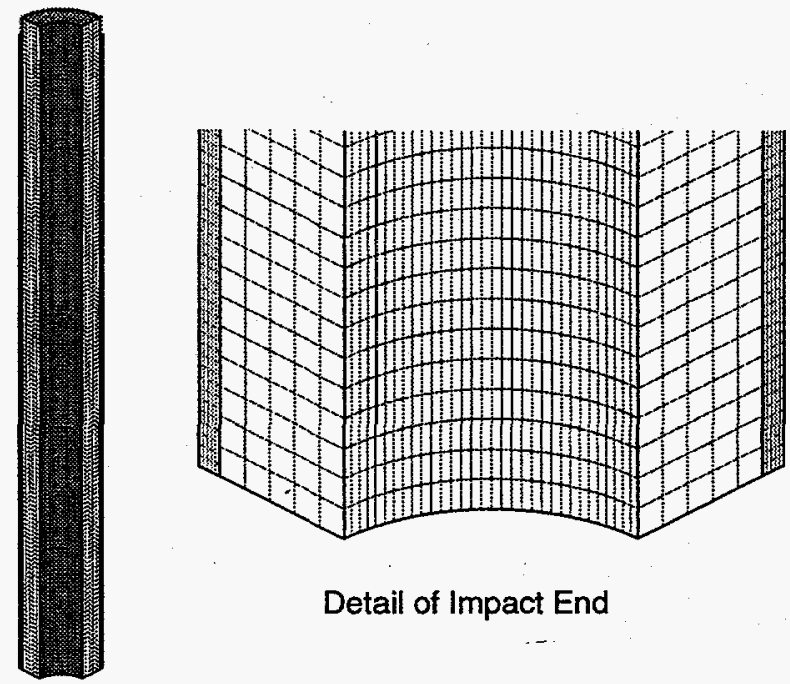

Detail of Impact End

\section{Quarter symmetric mesh used for PRONTO-3D analysis}

Figure 2: Finite element models used for PRONTO analyses of the lead-siump problem

ensure the impact direction is aligned with the axis of the cylinder, the tests were performed on a shock frame. Within this frame it is easier to have the cylinder resting on the stiff support and impact it with a falling mass.

A schematic and photo of the experimental set-up are shown in Fig. 3. A series of five tests were performed. The first test was an uninstrumented scoping test to assure the test article would perform as intended. The next four tests had 14 strain gages, 8 accelerometers, and a load cell to measure the response of the test unit and provide data to compare with the finite element solution. Accelerometers were placed on the impact table, the top platen, the bottom platen, and the support table. Two accelerometers were used in each location to provide 
redundant data. Strain gages were also attached to the cylinder to measure surface strains. Axial and hoop gages were installed in each quadrant around the bottom of the cylinder. These gages were used to determine if there are any radial asymmetries in the behavior of the cylinder. In addition, six axial strain gages were installed near the

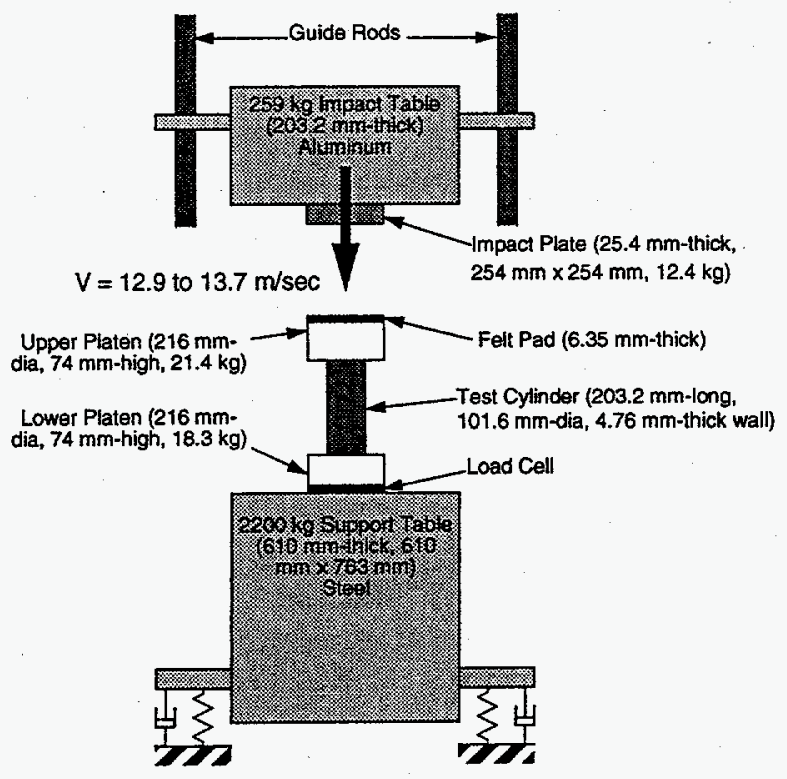

Schematic of test set-up

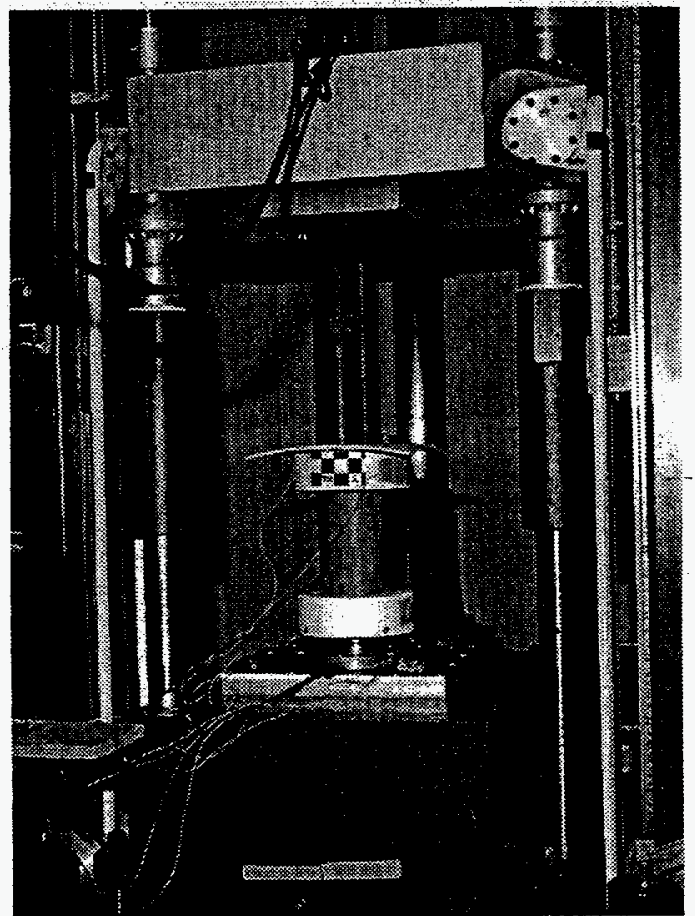

Photo of test unit before the impact table is raised to its drop height

Figure 3: Experimental set-up for the Large Inelastic Deformation Benchmark tests location were the largest buckle was predicted to occur. These gages were used to determine the profile of the buckle.

The tube begins to buckle relatively early in the impact. For a tube of these dimensions this buckling occurs after the walls are undergoing sustained plastic flow and there are four buckles along the length of the tube. As these buckles increase in size the hardening resistance is no longer sufficient to overcome the moment applied to the wall by the offset between the axial load and the centerline of the wall. When this happens one of the buckles becomes unstable and collapses. In the test series the buckle at the bottom collapsed in three of the tests and the buckle at the top collapsed in one of the tests (also in the scoping test).

Four nominally identical impact tests were conducted in the test series. For each of these tests the impact table was raised to a height above the test unit that had been calibrated to result in an impact velocity of $13.4 \mathrm{~m} / \mathrm{s}$. The impact table slides down on two guide tubes that incorporate a braking system to prevent secondary impacts after rebound. Because of slight variations in the friction between the impact table and the guide tubes and the force in the elastic ropes, the impact velocity for the four tests varied from $12.9 \mathrm{~m} / \mathrm{s}$ to $13.7 \mathrm{~m} / \mathrm{s}$. In the first, second, and fourth tests the top buckle became unstable and collapsed, the opposite of what had been seen in the scoping test. In the third test the bottom buckle collapsed. Figure 4 shows the post-test shapes for the four test units. This bi-modality of test results for nominally identical tests was very surprising. However, in each of the tests the accelerations and the loads from the load cell were nearly identical (See Fig. 5). Furthermore, the deformed shapes of the two test results, although inverted from top to bottom, were nearly identical. This implies the two results are mechanistically similar.

Several types of analyses were performed to compare different finite element codes and different element types. Analyses were performed using the finite element codes PRONTO-2D, PRONTO-3D, and ABAQUS Explicit (HKS, 1991). All of these codes are transient dynamics codes that use explicit integration to solve the equation of motion. Element types used are 2D axisymmetric 4-noded continuum elements, 2D axisymmetric 2-noded shell elements, 3D 8-noded continuum elements, and 3D 4-noded shell elements. The meshes used for these models are shown in Fig. 6. For all of the codes the stainless steel tube was modeled using a power-law hardening model, the other steels were modeled as elastic, and the felt pad was modeled using a linear hardening model.

Figures 7 and 8 show comparisons of the calculated deformed shapes with the deformed shape from one of the test units. The results in Fig. 7 are from the shell element calculations and the results in Fig. 8 are from

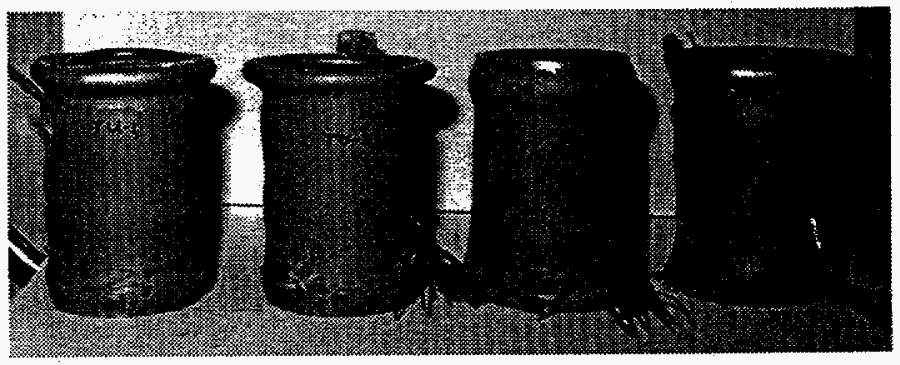

Figure 4: Deformed shape for the four test articles. 
the continuum element calculations. From these results it is seen that all of the finite element solutions closely agree with the test results for the location of the end buckles and for the size of the smaller buckle. Some of the solutions (ABAQUS Explicit 2D and $3 D$ continuum elements and PRONTO-3D continuum

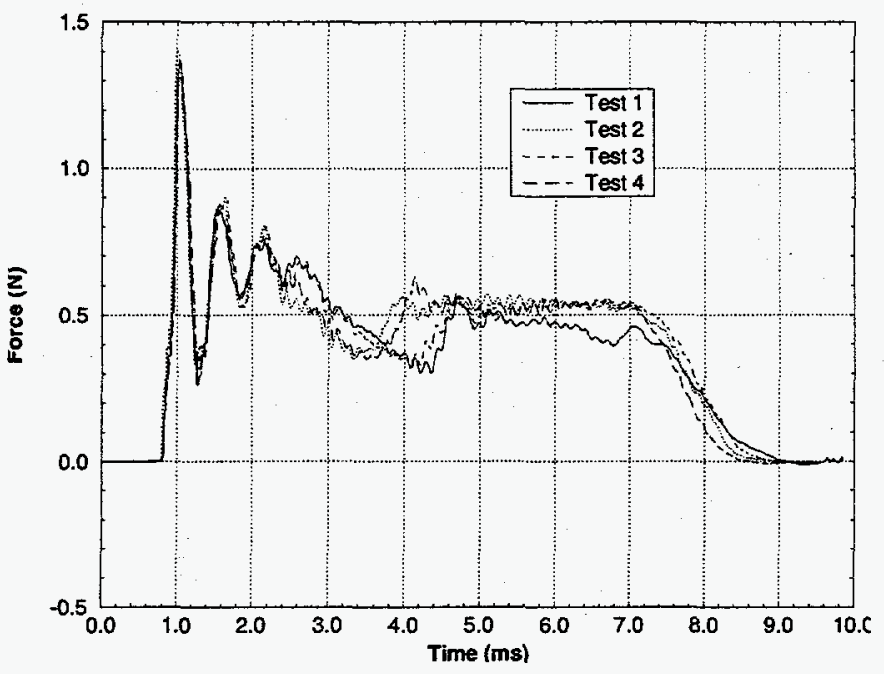

Figure 5: Load vs. time plots from the load cell for all four tests.
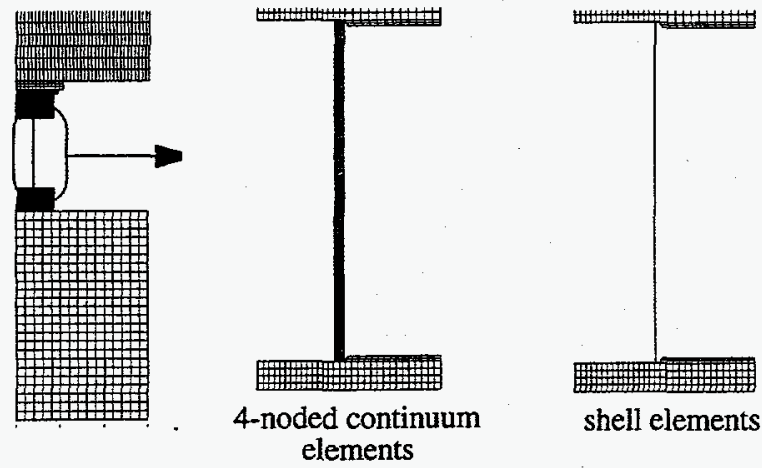

shell elements

2D Axisymmetric Models

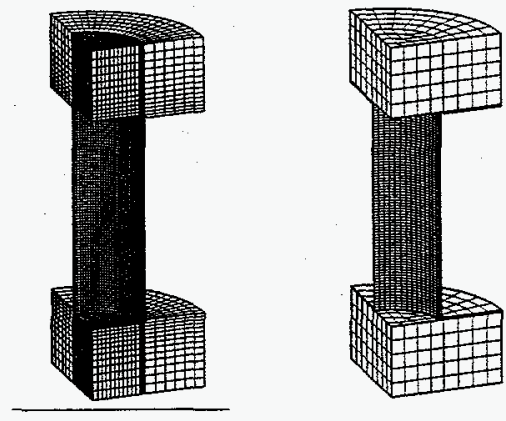

3D Models

Figure 6: Finite element models used for the study. elements) did not capture the instability that occurred in the buckle that collapsed. These solutions were slightly too stiff. A mesh refinement study was carried out using ABAQUS Explicit with $2 \mathrm{D}$ continuum elements to see if the excess bending stiffness of these models was due to the coarseness of the discretization. The initial 2D continuum element models had 5 elements through the thickness of the wall and 75 elements along the length of the wall. This was increased to 11 elements by 200 elements for the curve labelled ABAQUS/ Explicit (axi quads, finer mesh). This model agrees well with the test result and the PRONTO 2D result. This result indicates that the coarseness of the mesh is the reason these models did not capture the behavior of the test unit. No mesh refinement studies were carried out for the $3 \mathrm{D}$ models due to the expense of the calculations with models much larger than those used here.

\section{STRUCTURAL EVALUATION TEST UNIT}

The previous two benchmark problems have been for relatively simple structures. For the use of inelastic analysis in the design of structures as complex as radioactive material transportation packages, a

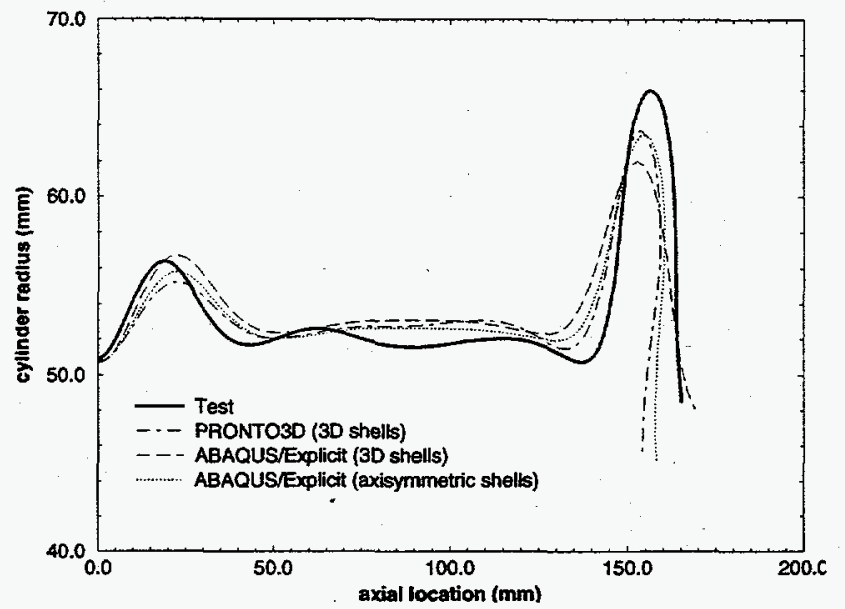

Figure 7: Profiles of shell element calculations compared to test.

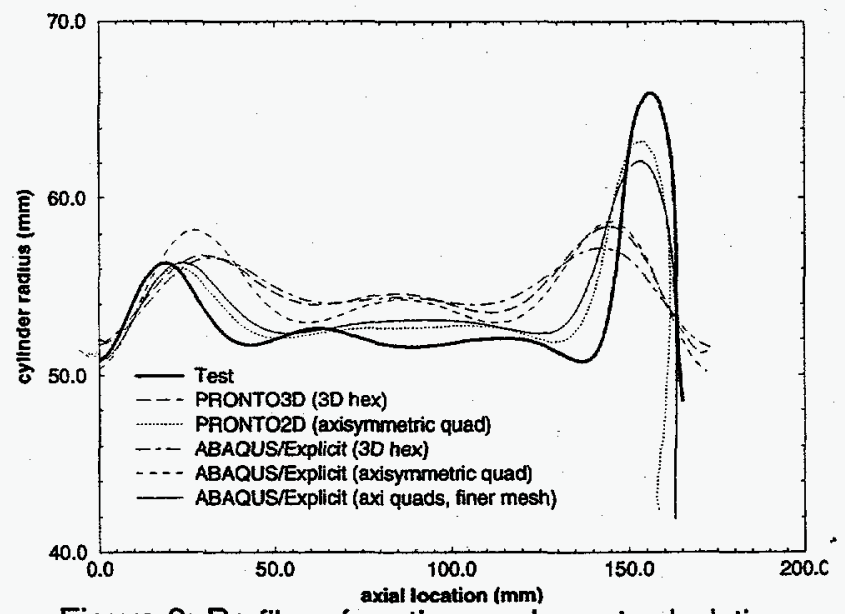

Figure 8: Profiles of continuum element calculations compared to test. 
benchmark problem with the interfaces and loadings typical of these packages is desired. A testing program at Sandia subjected a typical cask-type package (Structural Evaluation Test Unit) to a series of impacts. It was decided to attempt to predict the test results using the finite element method (Ludwigsen and Ammerman, 1995, Ammerman and Bobbe, 1995). The Structural Evaluation Test Unit was designed to just meet the design requirements of NRC Regulatory Guide 7.6 when subjected to a $13.4 \mathrm{~m} / \mathrm{s}$ impact in the end-on orientation. Tests were performed with velocities of $13.4,20.1$, and $26.8 \mathrm{~m} / \mathrm{s}$. An additional test was performed with an impact velocity of $26.8 \mathrm{~m} / \mathrm{s}$ with an impact angle of 7 degrees from vertical. The end-on impacts were modeled using PRONTO-2D and the 7 degree corner impact was modeled using PRONTO-3D. Figure 9 shows a schematic diagram of the test unit and Fig. 10 shows a typical test set-up. The finite element meshes used for the analyses are shown in Fig. 11. In this model the stainless steel cylinders and lids, the mild steel contents, and the lead shielding layer are all modeled using the power-law hardening model available in PRONTO. The impact limiter is modeled with an isotropic crush material model. Instrumentation for the tests consisted of hoop and axial strain gages near the impact end on the inside of the inner stainless steel shell and on the outside of the outer stainless steel shell. Accelerometers were located on each lid, the contents, and the outside of the test unit body at mid-height. Analysis and test results were compared for these transducers as well as for deformed shape of the test unit body.

For the $13.4 \mathrm{~m} / \mathrm{s}$ impact there was very little permanent deformation. The impact limiter successfully absorbed the majority of the kinetic energy from the drop. This test served to validate the design of the test unit. Typical transducer readings and analytical prediction are shown in

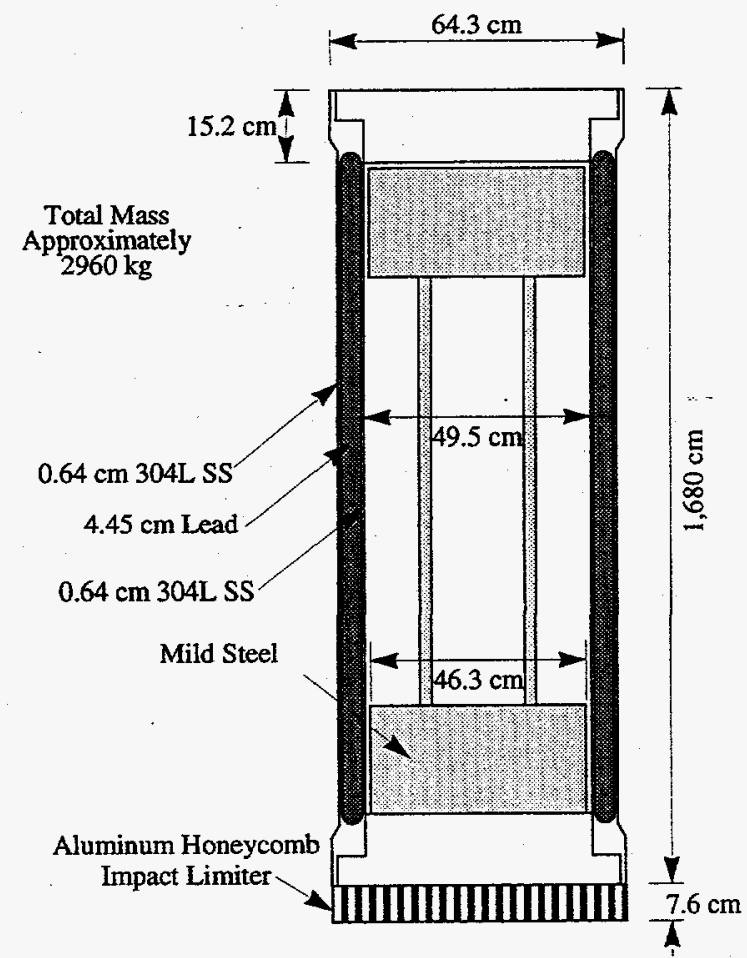

Figure 9: Schematic view of the Structural Evaluation Test Unit
Fig. 12. The analysis predicted the accelerations and the strains fairly well, matching both the peak acceleration and the peak strain. In the strain time history the test data indicates essentially no residual strain, while the analysis data indicates a residual strain level of about $600 \mu \varepsilon$.

For the $20.1 \mathrm{~m} / \mathrm{s}$ impact there was a slight amount of bulging of the test unit near the bottom of the lead column. This bulging was not sufficient to be obvious, but was noticed in the mechanical inspection of the test unit. The results of the bulging are apparent in the permanent strains measured in the test and predicted by the analysis. Figure 13 shows the analytical and test results. Again there is a very close match.

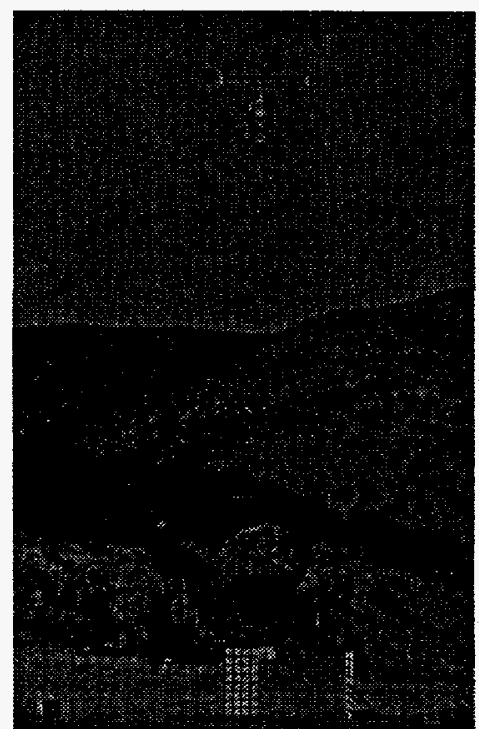

Figure 10: Typical test set-up for the Structural Evaluation Test Unit

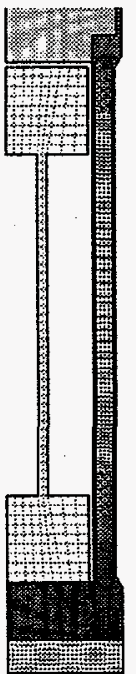

$2 \mathrm{D}$ axisymmetric model used for the axial impacts

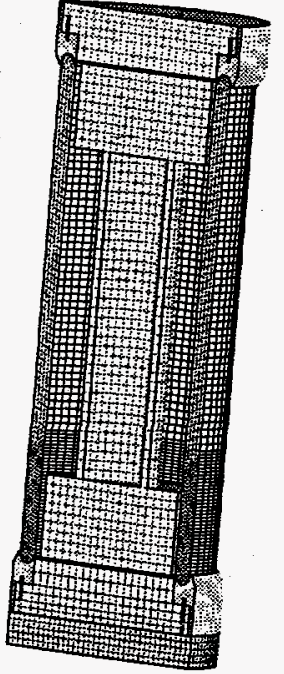

3D half symmetric model used for the comer impact
Figure 11: Finite element meshes used for the analysis of the Structural Evaluation Test Unit 

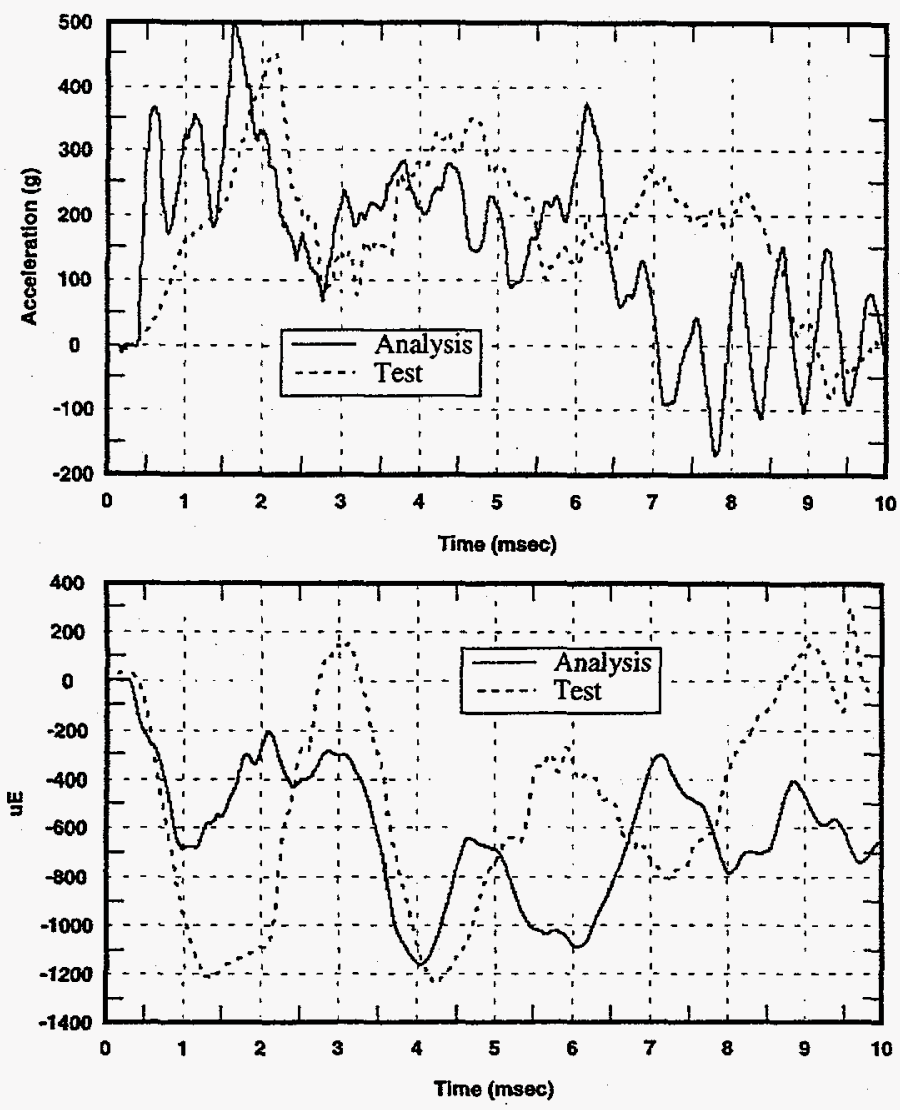

Figure 12: Analysis and test results for the $13.4 \mathrm{~m} / \mathrm{s}$ impact

In the axial $26.8 \mathrm{~m} / \mathrm{s}$ impact there was significant plasticity in the inner and outer shells of the test unit. The strain levels were sufficient to cause the strain gages to become debonded from the wall. In this test it is easy to compare the analysis and test results based on deformed shape, as the deformations are significant. Figure 14 shows a qualitative comparison between the test and predicted deformations. The measured accelerations of the test unit body are compared to the finite element prediction in Figure 15 . Both the test results and analysis prediction have been filtered with a low-pass filter using a $500 \mathrm{~Hz}$ cut-off frequency to eliminate the high-frequency chatter in the response.

The $26.8 \mathrm{~m} / \mathrm{s}$ corner drop was performed to have test data to validate 3D finite element analyses. Because of the comer impact, the deformations of the test unit were not symmetric, but rather there was a significantly greater amount of deformation on the side of initial impact than on the opposite side. There was a large outward buckle of the outer wall near the location of where the wall is welded to the closure flange. This buckle resulted in about a $6.3 \mathrm{~cm}$ shortening of the test unit on that side. Since the contents were only $1.2 \mathrm{~cm}$ shorter than the length of the internal cavity, this amount of test unit shortening indicates the contents were also shortened. The amount of force required to shorten the contents was sufficient to cause the closure bolts on the end opposite from impact to yield and elongate. Figure 16 shows a qualitative comparison between the test results and those predicted by the finite element analysis. There is close agreement between the two results. The measured accelerations of the test unit body are compared to the finite element prediction in Figure 17. Both the test results and analysis
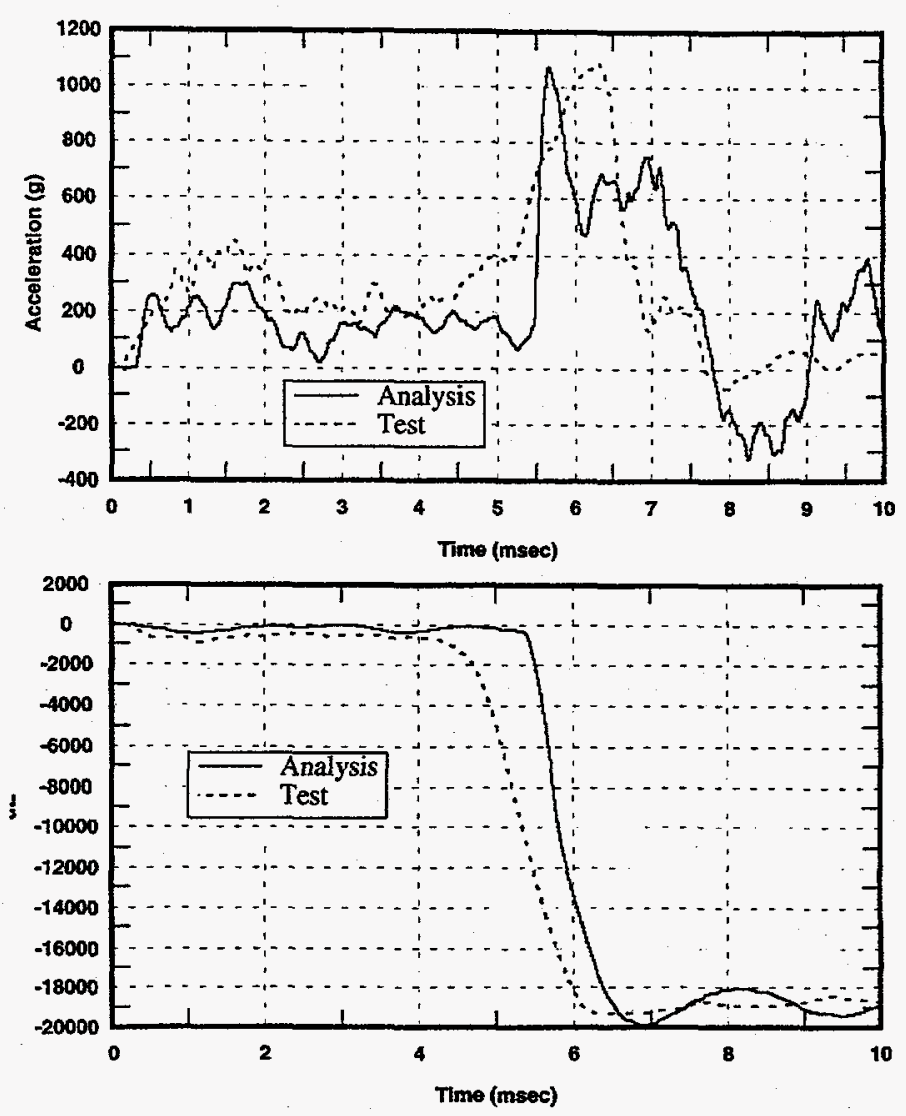

Figure 13: Analysis and test results for the $20.1 \mathrm{~m} / \mathrm{s}$ impact
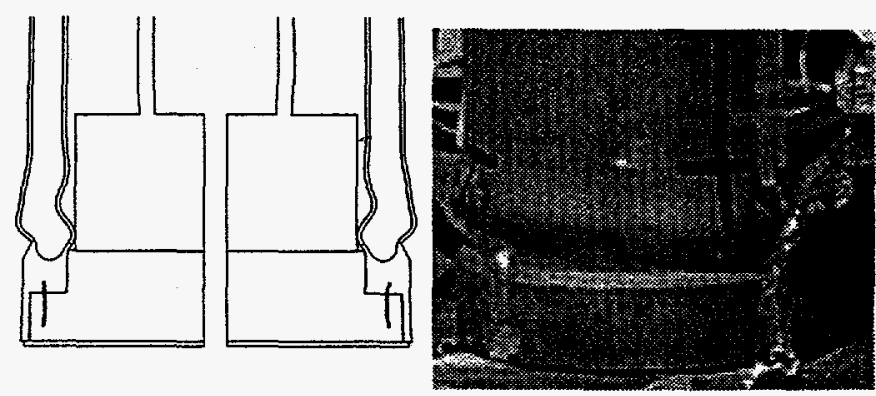

Figure 14: Analysis and test results for the $26.8 \mathrm{~m} / \mathrm{s}$ end impact

prediction have been filtered with a low-pass filter using a $500 \mathrm{~Hz}$ cutoff frequency to eliminate the high-frequency chatter in the response.

\section{CONCLUSIONS}

The advances made in the past few years in the power of computers, finite element codes, and constitutive modeling have made the nonlinear transient dynamic finite element technique a powerful tool for determining the response of structures to impact loads. The results of the benchmarking exercises discussed in this paper show that nonlinear transient dynamic finite element analyses are able to give good predictions of the response of the test units when subjected to impact accidents. These impacts are similar to the impact test required for radioactive material transportation packages and extra-regulatory 


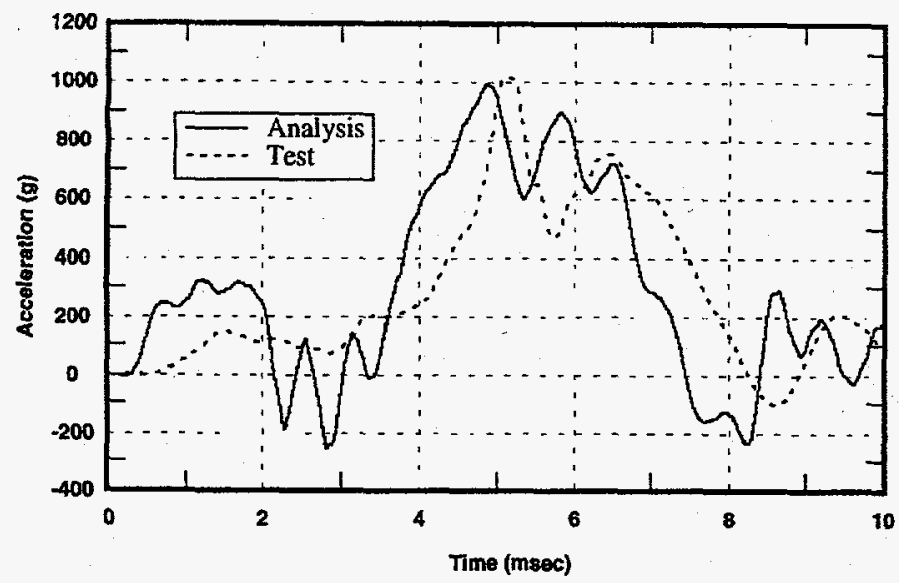

Figure 15: Analysis and test accelerations for the $26.8 \mathrm{~m} / \mathrm{s}$ end impact
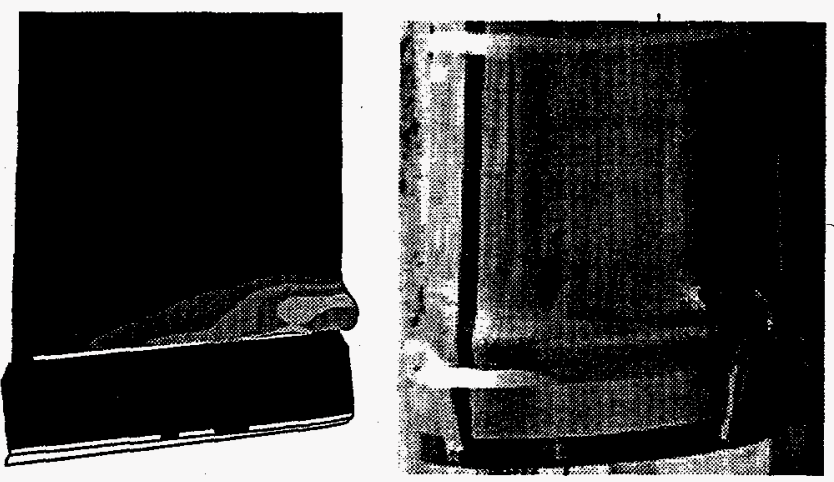

Figure 16: Analysis and test results for the $26.8 \mathrm{~m} / \mathrm{s} 7$ degree corner impact

impact accidents required for risk assessments. Various finite element codes have been compared and are shown to be in close agreement for two of the problems. Results such as these are available to increase the confidence in the use of the inelastic finite element technique in the design and certification of radioactive material transportation packages. These results can also be used for demonstrating the ability of the finite element method to accurately capture the response of other items subjected to impact loadings. The use of the nonlinear transient dynamic finite element technique provides designers with a method to determine the true response of packages to the hypothetical accident and other impact conditions. Since most packages today are certified by a combination of analysis and tests, having an analysis tool that is able to predict the test results should make the design-test-certify process more efficient.

\section{REFERENCES}

Ammerman, D. J. and Bobbe, J. G., 1995, "Testing of the Structural Evaluation Test Unit," Proceedings of the PATRAM '95 conference, Las Vegas, NV.

Glass, R. E., 1985, "Structural Code Benchmarking for the Analysis of Impact Response of Nuclear Material Shipping Casks," Technical Report SAND 84-1855C, Sandia National Laboratories, Albuquerque, NM.

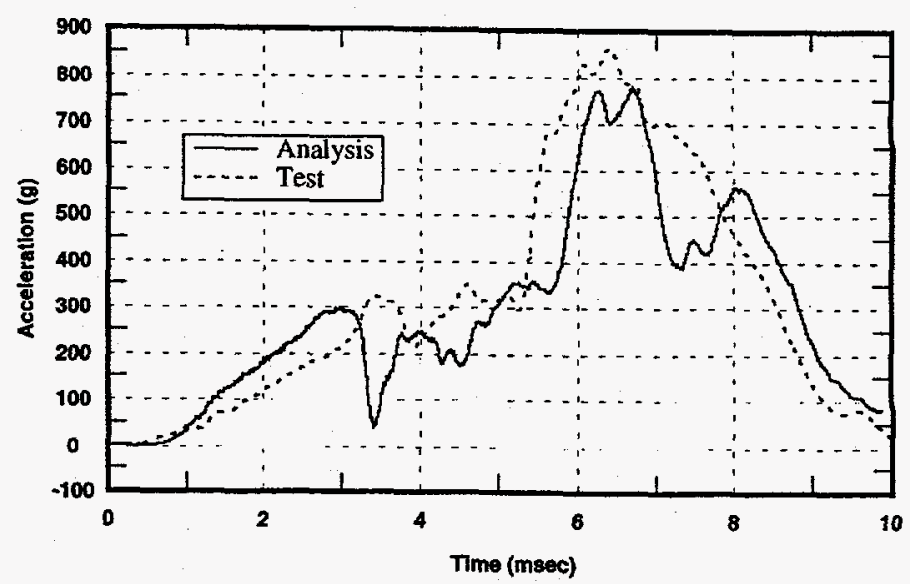

Figure 17: Analysis and test accelerations for the $26.8 \mathrm{~m} / \mathrm{s}$ 7 degree corner impact

HKS, 1991, “ABAQUS/Explicit Users' Manual," Hibbitt Karlson, and Sorensen, Inc., Pawtucket, RI.

Hoffman, E. L. and Ammerman, D. J., 1995,"Dynamic Pulse Buckling of Cylindrical Shells under Axial Impact: A Comparison of 2D and 3D Finite Element Calculations with Experimental Data," Technical Report SAND93-0350, Sandia National Laboratories, Albuquerque, NM.

Ludwigsen, J. S. and Ammerman, D. J., 1995, "Analytical Determination of Package Response to Severe Impacts," Proceedings of the PATRAM '95 conference, Las Vegas, NV.

Taylor, L. M., and Flanagan, D. P., 1987, "PRONTO2D: A Twodimensional Transient Solid Dynamics Program," Technical Report SAND86-0594, Sandia National Laboratories, Albuquerque, NM.

Taylor, L. M., and Flanagan, D. P., 1989, "PRONTO3D: A Threedimensional Transient Solid Dynamics Program," Technical Report SAND87-1912, Sandia National Laboratories, Albuquerque, NM. 